\title{
Plasma N-Terminal Pro-Brain Natriuretic Peptide as Prognostic Marker in Fatal Cardial Decompensation with Sunitinib Malate Therapy
}

\author{
Michael Staehler Nicolas Haseke Katja Zilinberg Thomas Stadler \\ Christian G. Stief \\ Department of Urology, University of Munich, Klinikum Grosshadern, Munich, Germany
}

\section{Key Words}

Renal cell cancer $\cdot$ Sunitinib $\cdot$ Cardiac failure $\cdot$ Side effects

\begin{abstract}
A 74-year-old man with metastatic renal cell carcinoma and a history of cardiac failure was treated with sunitinib malate. MUGA echocardiography could not detect a relevant change in the ejection fraction although the clinical situation of the patient worsened dramatically. The only parameter to hint at the deteriorated cardiac function was plasma $\mathrm{N}$-terminal pro-brain natriuretic peptide (BNP). Finally, the patient died after only one cycle of sunitinib treatment. We propose to prospectively include BNP for the early detection of cardiovascular decompensation in high-risk patients. Future studies concerning the relevance of BNP in drug-related cardiotoxicity are urgently needed.
\end{abstract}

Copyright $\odot 2010$ S. Karger AG, Basel

\section{Introduction}

Sunitinib malate has demonstrated high efficacy in metastatic renal cell carcinoma (mRCC). Compared to interferon therapy, progression-free survival was doubled with a trend towards improved overall survival [1].
This high efficacy is accompanied by a new set of side effects. In the pivotal phase III mRCC trial, updated data indicates that $21 \%$ of sunitinib-treated patients experienced a reversible decline in left ventricular ejection fraction to below normal [2]. Although we were aware of cardiac toxicity, we had to experience a surprising course of a patient which we report here.

\section{Case Report}

A 74-year-old male patient was admitted with bilateral disseminated lung metastases and mediastinal and hilar lymph node metastases from clear cell RCC. Recurrent RCC was also suspected in the left kidney. The initial diagnosis of RCC was made 5 years prior to detection of metastases when right-sided radical nephrectomy including lymphadenectomy and adrenalectomy was performed and revealed pT3a $(7 \mathrm{~cm})$ pN0 cM0 G2 R0 clear cell RCC. Surgery was complicated by perioperative resuscitation due to ventricular tachyarrhythmia. Three years after nephrectomy the patient suffered from myocardial infarction and consecutively developed dilatative cardiomyopathy. He was given a pacer (AICD). Further anamnesis included chronic pulmonary obstructive disease and insulin-independent diabetes mellitus. The patient was in a good clinical condition with a Karnofsky index of $80 \%$ and occasionally worked as a gardener.

Prior to systemic therapy, MUGA echocardiography was performed which revealed a dilated left ventricle with a reduction of the ejection fraction to $42 \%$. The dorsal wall was hypokinetic with

\section{KARGER}

Fax +4161306 1234

E-Mail karger@karger.ch

www.karger.com
(C) 2010 S. Karger AG, Basel

0042-1138/10/0841-0119\$26.00/0

Accessible online at:

www.karger.com/uin
Michael Staehler, MD

Department of Urology, University of Munich, Klinikum Grosshadern

Marchioninistrasse 15, DE-81377 München (Germany)

Tel. +49 897095 3722, Fax +49897095 6722

E-Mail michael.staehler@med.uni-muenchen.de 


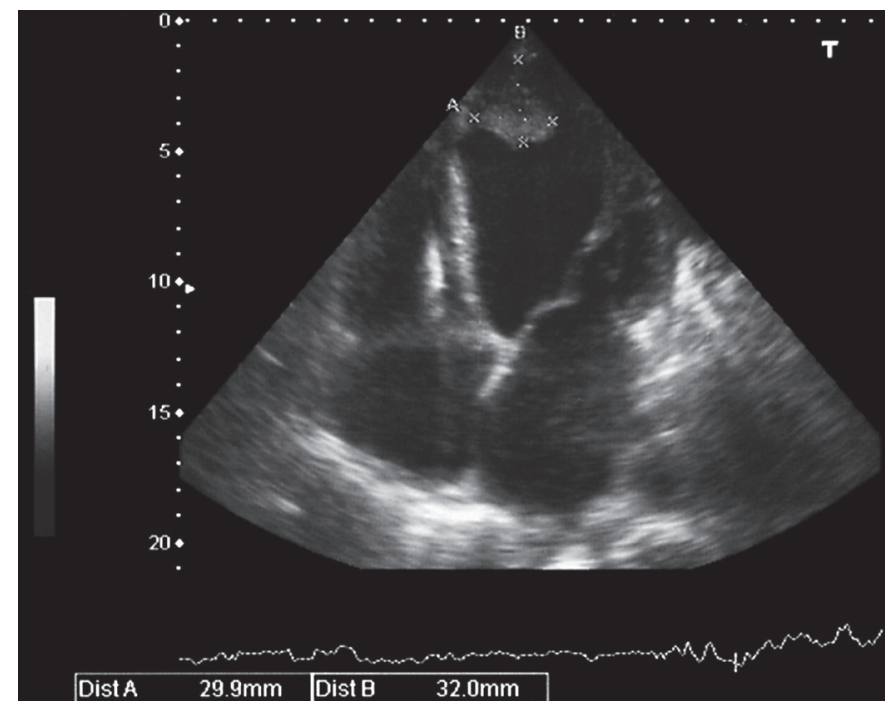

Fig. 1. Left ventricular thrombus with a size of $29.9 \times 32.0 \mathrm{~mm}$ in subsequent cardial echography (first control after one cycle of sunitinib therapy).

a small thrombus of $2.6 \times 0.6 \mathrm{~cm}$, primarily overlooked in the initial computed tomography. Further grade I insufficiency of the mitral and tricuspid valves was seen.

The patient was $170 \mathrm{~cm}$ tall and weighed $69 \mathrm{~kg}$. Initial blood pressure was 105/70 $\mathrm{mm} \mathrm{Hg}$. Medication consisted of ramipril 2.5 mg b.i.d., bisoprolol $2.5 \mathrm{mg}$ b.i.d., furosemide $20 \mathrm{mg}$ o.d., aspirin $100 \mathrm{mg}$ o.d., and pravastatin $20 \mathrm{mg}$ o.d. Initial serum chemistry showed normal values for sodium, potassium, calcium, BNP $(6,700 \mathrm{pg} / \mathrm{ml}), \mathrm{CRP}$, creatinine, AST, ALT, AP, LDH, albumin, serum protein and TSH. Blood chemistry showed a lowered hemoglobin level of $13.6 \mathrm{~g} / \mathrm{dl}$ with normal values for thrombocytes and leukocytes.

The situation was intensively discussed with the patient and he was started on sunitinib with the knowledge of an increased risk for a cardiac event. Therapy was initially well-tolerated without development of hypertension. The only adverse event seen was discrete peripheral edema that was treated with a slight increase of the diuretic therapy. In week 4 of the first treatment course, the patient's general condition worsened with complete recovery in the planned 2 -week therapeutic break of sunitinib therapy.

After one cycle, MUGA echocardiography was controlled and revealed an ejection fraction of $36 \%$. The preexisting thrombus had grown to $3.0 \times 3.2 \mathrm{~cm}$ (fig. 1). In serum chemistry, plasma $\mathrm{N}$-terminal pro-brain natriuretic peptide (BNP) had increased to $27,000 \mathrm{pg} / \mathrm{ml}$ with all other parameters unchanged. To prevent further thrombosis the patient was started on coumarin with an INR of 2.0 .

Three days after restarting sunitinib therapy the patient's general condition deteriorated and he had to be admitted to the ward. Progressive cardiac failure with central venous congestion developed. Consecutively, liver-compensated failure developed and renal function deteriorated without the need for dialysis. BNP in- creased to $45,000 \mathrm{pg} / \mathrm{ml}$. Sunitinib was immediately withdrawn. No deep vein thrombosis was seen but the left ventricular thrombus had grown to $3.5 \times 4.0 \mathrm{~cm}$ without a change in ejection fraction. After a further radiological diagnostic evaluation, no progression of the disease was seen. The patient died 8 weeks after initiation of sunitinib therapy with only one cycle and 3 days of systemic treatment due to progressive heart failure.

\section{Discussion}

Cardiac side effects are commonly described with tyrosine-kinase inhibition therapy for $\mathrm{mRCC}$, some of which may be fatal. In the first publication on sunitinib efficacy as a second-line indication [3], 1 of 106 patients was suspected to have died from a cardial event, but no further information on this incident was obtainable. Thus, study protocols performed with tyrosine-kinase inhibitor drugs thoroughly control electrocardiograms and echocardiography to detect changes in the ejection fraction.

In a retrospective analysis at Stanford, 7 of 48 patients (15\%) developed grade $3 / 4$ heart failure. Of these patients, 3 had persistent cardiac dysfunction after discontinuation of sunitinib and initiation of heart failure therapy. A history of congestive heart failure, coronary artery disease and lower body mass index were factors associated with increased risk [2].

Although most of the cardiac events are controllable, some patients do not recover from the cardiac changes induced by the therapy and thus can no longer be treated with the selected drug [4]. There is evidence that the switch to another multi-kinase inhibitor will not overcome this situation [5]. BNP has been shown to be consistently associated with an increased risk of all-cause mortality in patients with congestive heart failure, even in those cases where no change in the ejection fraction can be seen $[6,7]$.

The only parameter in our patient to reveal the cardiac function and the dramatic course was BNP in serum chemistry. Therapy was restarted after clinical recovery of the patient without this parameter being considered. We propose to prospectively include BNP as a diagnostic tool for early detection of cardiovascular decompensation in high-risk patients. Future studies concerning the relevance of BNP in drug-related cardiotoxicity are urgently needed. 


\section{References}

1 Motzer RJ, Hutson TE, Tomczak P, Michaelson MD, Bukowski RM, Rixe O, Oudard S, Negrier S, Szczylik C, Kim ST, Chen I, Bycott PW, Baum CM, Figlin RA: Sunitinib versus interferon-alfa in metastatic renal-cell carcinoma. N Engl J Med 2007;356:115-124.

2 Telli ML, Witteles RM, Fisher GA, Srinivas $S$ : Cardiotoxicity associated with the cancer therapeutic agent sunitinib malate. Ann Oncol 2008;19:1613-1618.

3 Motzer RJ, Rini BI, Bukowski RM, Curti BD, George DJ, Hudes GR, Redman BG, Margolin KA, Merchan JR, Wilding G, Ginsberg MS, Bacik J, Kim ST, Baum CM, Michaelson MD: Sunitinib in patients with metastatic renal cell carcinoma. JAMA 2006;295:25162524.
4 Staehler M, Haseke N, Schoppler G, Stadler T, Heinemann G, Stief CG: Managing the side effects of angiogenetic inhibitors in metastatic renal cell carcinoma (in German). Urologe A 2006;45:1333-1343.

5 Mego M, Reckova M, Obertova J, SycovaMila Z, Brozmanova K, Mardiak J: Increased cardiotoxicity of sorafenib in sunitinib-pretreated patients with metastatic renal cell carcinoma. Ann Oncol 2007;18:1906-1907.
6 Hartmann F, Packer M, Coats AJ, Fowler MB, Krum H, Mohacsi P, Rouleau JL, Tendera M, Castaigne A, Anker SD, AmannZalan I, Hoersch S, Katus HA: Prognostic impact of plasma N-terminal pro-brain natriuretic peptide in severe chronic congestive heart failure: a substudy of the Carvedilol Prospective Randomized Cumulative Survival (Copernicus) trial. Circulation 2004; 110:1780-1786.

7 Paul B, Soon KH, Dunne J, De Pasquale CG: Diagnostic and prognostic significance of plasma N-terminal-pro-brain natriuretic peptide in decompensated heart failure with preserved ejection fraction. Heart Lung Circ 2008; 17:497-501. 